\title{
Quaternization Reaction of 2-Vinylpyridine and 4-Vinylpyridine Network Copolymers for 4-Nitrophenol Adsorption
}

\author{
Adriana S. S. Rodrigues, ${ }^{a}$ Alcino P. de Aguiar, ${ }^{* a}$ Mônica R. M. P. de Aguiar ${ }^{b}$ and \\ Luiz Claudio de Santa Maria ${ }^{*, b}$ \\ ${ }^{a}$ Departamento de Engenharia Química, Instituto Militar de Engenharia, Praça General Tibúrcio, 80, \\ 22290-270 Rio de Janeiro-RJ, Brazil \\ ${ }^{b}$ Instituto de Química, Universidade do Estado do Rio de Janeiro Rua São Francisco Xavier, 524, \\ 20559-900 Rio de Janeiro-RJ, Brazil
}

\begin{abstract}
Este artigo avalia o emprego de copolímeros porosos (a base de estireno-STY e vinilpiridina-VP, reticulados com divinilbenzeno-DVB) como adsorventes de 4-nitrofenol de soluções aquosas. Os copolímeros foram sintetizados através de polimerização em suspensão aquosa via radical livre na presença de heptano (HEP) e tolueno (TOL) em diferentes proporções como agentes porogênicos. As unidades de VP nos copolímeros foram modificadas quimicamente pela adição eletrofílica de monômeros vinílicos funcionalizados (acrilonitrila). Os copolímeros quaternizados foram caracterizados por espectrofotometria na região do infravermelho (FTIR), análise elementar $(\mathrm{CHN})$, microscopia ótica $(\mathrm{OM})$ e microscopia eletrônica de varredura (SEM).

This article aims to evaluate porous copolymers (based on styrene-STY and vinylpyridine$\mathrm{VP}$, cross-linked with divinylbenzene-DVB) as adsorbents for 4-nitrophenol from aqueous solution. These copolymers were synthesized by suspension polymerizations in the presence of heptane (HEP) and toluene (TOL) in different proportions as porogenic agents. The VP units of the copolymers were chemically modified by the addition of the electrophilic ethylenic compound (acrylonitrile). The quaternized copolymers were characterized by infrared spectrometry (FTIR), elemental analysis $(\mathrm{CHN})$, optical microscopy $(\mathrm{OM})$ and scanning electron microscopy (SEM).
\end{abstract}

Keywords: porous polymer beads, quaternization reactions, vinylpyridine

\section{Introduction}

From the polar compounds which are of environmental interest, the phenolic ones belong to a group that has been receiving increasing attention, due to its toxicant action, even in small concentrations. These compounds come from wide industrial sources, such as degradation products of many chlorinated pesticides ${ }^{1,2}$ and biodegradation products of natural substances (humus and tanning barks). ${ }^{3}$ Amongst some applications of nitro-phenols in the different processes, can be listed: manufacture of dyes, pigments, products of rubber, fungicides, explosives, manufacture of medicines, and in tannery. ${ }^{4}$ These compounds present significant water solubility due to their polarity. The recoveries for polar compounds are higher when chemically modified hydrocarbon copolymers or

*e-mail: alcino@ime.eb.br; santamaria@pesquisador.cnpq.br copolymers containing polar monomer units (such as acrylonitrile, vinylpyridine etc.) are employed. The hydrocarbon chains make the surface hydrophobic and so there is little surface contact with aqueous solutions. On the other hand, the modified hydrocarbon copolymers (or polar copolymer) have a hydrophilic surface containing a relatively large number of active aromatic sites (divinylbenzene and/or styrene units) which allow $\pi-\pi$ interactions with these aromatic pollutants and also allow polar interactions (hydrogen bonding, dipole-dipole, charge transfer and acid-base complexation). ${ }^{5}$

Polymers of 4-vinylpyridine (4VP) or 2-vinylpyridine (2VP) have been known for many years and have found several industrial as well as laboratorial applications. ${ }^{6,9}$ The porous anion exchangers based on 4VP or 2VPdivinylbenzene (DVB) copolymers show better thermal, chemical and radiation stabilities when compared to conventional anion exchangers based on styrene (STY)DVB. ${ }^{6,10}$ These cross-linked copolymers are efficient 
adsorbents in the removal of inorganic and organic pollutants from wastewater, including pathogenic microorganisms (virus, bacteria, fungus). ${ }^{6,10-12}$ These copolymers have the advantage of complexing different oxidizing agents by immobilizing them. ${ }^{13-15}$

The 2VP or 4VP-DVB copolymer beads are synthesized by suspension polymerization technique and the porosity in the beads is controlled by mixing some inert organic liquid named diluent with monomers. ${ }^{12-18}$ Two of the most desirable properties of any ion-exchanger are: high ionexchange capacity and fast ion-exchange kinetics. These characteristics could be obtained in the network materials by the functional groups present in the chemical structure and by their porosity. Although cross-linked pyridinic resins are hydrophilic, their water affinity could be increased by the quaternization of pyridine. ${ }^{19,20}$ These chemical modifications increase the resin hydrophilicity, enabling the resin to be used directly without a wetting process.

Our interest in the potential use of 2-VP or 4VP-DVB resins and their quaternized derivatives as adsorbents for 4-nitrophenol led us to prepare a number of copolymers based on 2VP or 4VP, STY and DVB as well as their quaternized derivatives with acrylonitrile.

\section{Experimental}

\section{Materials}

Styrene was kindly donated by Petroflex and used as received. Commercial DVB (grade of $50 \%$ of DVB, containing a mixture of DVB and ethylvinylbenzene isomers), 2VP (from Nitriflex, Brazilian Co.) and 4VP (from SigmaAldrich) were distilled. $\alpha, \alpha$ '-Azo-bis-isobutyronitrile (AIBN, donated by Metacril, Brazilian Co.) was purified by recrystallization from methanol. 2-hydroxyethyl-celullose (HEC, Cellosize QP-100MH) was donated by Union Carbide and used as received. The other reagents were commercially purchased, namely gelatin, $n$-butanol, propanone, methanol, 4-nitrophenol, $\mathrm{NaCl}, n$-heptane (HEP), toluene (TOL) from
Vetec Química Fina Ltda (Brazil) with P.A. degree and used as received. Aqueous solutions were prepared using distilled deionized water.

\section{Copolymers synthesis}

The aqueous suspension copolymerizations of 2VP/STY/ DVB and 4VP/STY/DVB were carried out in a $1 \mathrm{~L}$, threenecked, round-bottomed flask glass reactor fitted with mechanical stirrer, reflux condenser with a silicon oil seal at its top. Aqueous phase (AP) was composed by gelatin and 2hydroxyethyl-celullose (at 0.15 or 0.25 wt.\% in relation to $\mathrm{AP}$, respectively) and $\mathrm{NaCl}$ ( 2 wt.\% in relation to $\mathrm{AP}$ ). The organic phase (OP) was composed by monomers mixture at varied compositions (total amount $=0.7 \mathrm{~mol}$ ), diluents (60HEP/40TOL or $40 \mathrm{HEP} / 60 \mathrm{TOL}$ at $100 \% \mathrm{v} / \mathrm{v}$ in relation to the monomers) and $\alpha, \alpha^{\prime}$-azo-bis-isobutyronitrile (AIBN) used as initiator ( $1.0 \mathrm{~mol} \%$ in relation to the monomers). OP was added slowly to AP previously prepared under stirring at room temperature $\left(25^{\circ} \mathrm{C}\right)$, employing $\mathrm{AP} / \mathrm{OP}$ ratio $=3 / 1$. These two phases were maintained under stirring (300 rpm) at room temperature $\left(25{ }^{\circ} \mathrm{C}\right)$ during $10 \mathrm{~min}$. After, the suspension copolymerization system was kept under stirring at $70{ }^{\circ} \mathrm{C}$ during 24 hours. The resin beads were thoroughly washed with hot water ( 8 portions of $500 \mathrm{~mL}$ ) and Soxhlet extracted with propanone and dried at $60{ }^{\circ} \mathrm{C}$. Table 1 summarizes the synthesis parameters. The differences in the yields can be explained by the losses of small particles during the washing step.

\section{Quaternization reactions}

The quaternizations of 2VP or 4VP copolymers beads were carried out by the Michael addition reaction of pyridine ring to the carbon-carbon double bond of acrylonitrile. The quaternization degree in the final copolymer was determined from the results of elemental analysis. The addition reactions were performed at $50{ }^{\circ} \mathrm{C}$ in a glass round-bottomed flask equipped with a stirrer, reflux condenser and thermometer.

Table 1. Compositions of the polymerization mixtures of 2 or 4 -vinylpyridine copolymers

\begin{tabular}{lcccc}
\hline Copolymer & \multicolumn{2}{c}{ Organic phase composition } & & \\
\cline { 2 - 4 } & $\begin{array}{c}\text { VP/STY/DVB } \\
\text { Monomers/(mol\%) }\end{array}$ & $\begin{array}{c}\text { Diluents/ } \\
(\% \mathrm{v} / \mathrm{v}, \text { HEP/TOL })\end{array}$ & Yield/(\%) & $\begin{array}{c}\text { N experimental } \\
\text { content/(\%) }\end{array}$ \\
\hline $\mathrm{C} 1^{\mathrm{a}}$ & 2VP 60/20/20 & $60 / 40$ & 68 & 5.6 \\
$\mathrm{C}^{\mathrm{b}}$ & 2VP 60/20/20 & $60 / 40$ & 95 & 7.5 \\
$\mathrm{C}^{\mathrm{b}}$ & 4VP 60/20/20 & $60 / 40$ & 79 & 7.5 \\
$\mathrm{C}^{\mathrm{b}}$ & 4VP 60/20/20 & $40 / 60$ & 95 & 7.2 \\
\hline
\end{tabular}

$2 \mathrm{VP}=2$-vinylpyridine; 4VP = 4-vinylpyridine; $\mathrm{STY}=$ styrene; $\mathrm{DVB}=$ divinylbenzene; $\mathrm{HEP}=n$-heptane; $\mathrm{TOL}=$ toluene; ${ }^{\text {a } 0.15 \%}$ of $\mathrm{HEC}$ and gelatin; ${ }^{\mathrm{b}} 0.25 \%$ of HEC and gelatin; ${ }^{\mathrm{c}}$ copolymers yield; ${ }^{\mathrm{d}}$ Determined by elemental analysis $(\mathrm{CHN}) \% \mathrm{~N}=[100(14 \mathrm{mVP} / \mathrm{mr} \mathrm{molVP})]$, where $\mathrm{mVP}=2 \mathrm{VP}$ or $4 \mathrm{VP}$ mass; $\mathrm{mr}=$ resin mass; molVP $=$ molar mass of $2 \mathrm{VP}$ or $4 \mathrm{VP} ; \mathrm{N}$ theorical content $=7.6 \%$; standard error $=0.5 \%$. 
The copolymer beads ( $1 \mathrm{~g}$ ) were poured into the flask, and then methanol, 1 mol L-1 aqueous $\mathrm{HCl}$ solution and acrylonitrile were added. After stirring during determined time reaction, the beads were filtered out, followed by through washing with water and then with propanone. The washed beads were dried in an oven at $60^{\circ} \mathrm{C}$ for $24 \mathrm{~h}$.

\section{Resin characterization}

The apparent density $\left(\mathrm{d}_{\mathrm{a}}\right)$ and swelling degree were determined in a graduated cylinder. ${ }^{21}$ The specific surface area was determined by BET method (ASAP Micromeritics 2010) and Mercury porosimetry (Autopore 9420 Micromeritics). The average pore diameter and pore volume were determined by $\mathrm{BJH}$ method from low-temperature nitrogen adsorption/desorption isotherms, which were obtained at $77 \mathrm{~K}$ using a high-vacuum volumetric apparatus. The samples were degassed at $80{ }^{\circ} \mathrm{C}$ under $1 \mathrm{mPa}$ for $3 \mathrm{~h}$. The unmodified and modified resins were characterized by elemental analysis (CHN Perkin-Elmer 2400) and infrared spectroscopy (FT-IR Perkin-Elmer 1720×) in $\mathrm{KBr}$ pellets. The morphological and visual appearance characteristics were observed by scanning electron microscopy (JEOL-JSM-5800LV). The beads were coated with carbon film and their external and internal parts were observed using $15 \mathrm{kV}$ acceleration electron beam.

\section{4-Nitrophenol adsorption}

The 4-nitrophenol adsorption was performed in nonbuffered conditions. In these experiments, a weighed quantity $(0.3 \mathrm{~g})$ of the copolymer was added to $25 \mathrm{~mL}$ of the 4-nitrophenol aqueous solution at $100 \mathrm{mg} \mathrm{L}^{-1}$. The mixture was shaken (in a continuous shaker) for 30,60 or $180 \mathrm{~min}$. The adsorption experiments were conducted in three different $\mathrm{pH}$ values, namely 3.0; 5.6 and 8.0. The 4-nitrophenol concentration was determined by highpressure liquid chromatography (HPLC) using a Varian Chromagraph, mod. 9050, equipped with UV 9012 detector and Bondesil-Varian C18 column (5um, $4.6 \times 15 \mathrm{~cm}, 6 \mathrm{kpsi})$. An isocratic mobile phase of acetonitrile $(\mathrm{ACN})$ and water $\left(\mathrm{ACN}: \mathrm{H}_{2} \mathrm{O}=50: 50\right)$ was used at a flow rate of $1 \mathrm{~mL} \mathrm{~min}^{-1}$ (loop of $5 \mu \mathrm{L}$ ). Detection was carried out at the wavelength of $280 \mathrm{~nm}$.

\section{Results and Discussion}

In order to prepare $2 \mathrm{VP}$ or $4 \mathrm{VP} / \mathrm{STY} / \mathrm{DVB}$ resins with porous structures, the suspension copolymerizations were carried out in a mixture of organic solvents (Table 1). The $\mathrm{C} 1$ resin was prepared using $0.15 \%$ of the stabilizing agent
(HEC and gelatin). The elemental analysis of this copolymer (Table 1) has shown low nitrogen incorporation (5.6\%), considering the theoretical values (7.6\%). The SEM of this resin (Figure 1a) shows beads with a large range in size. This broad particle size distribution is a feature of suspension polymerization process. ${ }^{22}$ Therefore, the next resins were developed using higher amounts of stabilizer (C2, C3 and $\mathrm{C} 4$ in Table 1). These reactions have incorporated almost $100 \%$ of the polar monomers (2VP and 4VP). The FTIR spectrum of copolymers presents absorption bands at 15901430 and $749 \mathrm{~cm}^{-1}$ (2VP) or $820 \mathrm{~cm}^{-1}$ (4VP) attributed to the symmetric $\mathrm{C}=\mathrm{N}$ stretching vibration and $\mathrm{C}-\mathrm{H}$ out-of plane bending vibration of pyridine ring in VP chain units, respectively, ${ }^{23}$ confirming the incorporation of $2 \mathrm{VP}$ or $4 \mathrm{VP}$ into the copolymer structure.
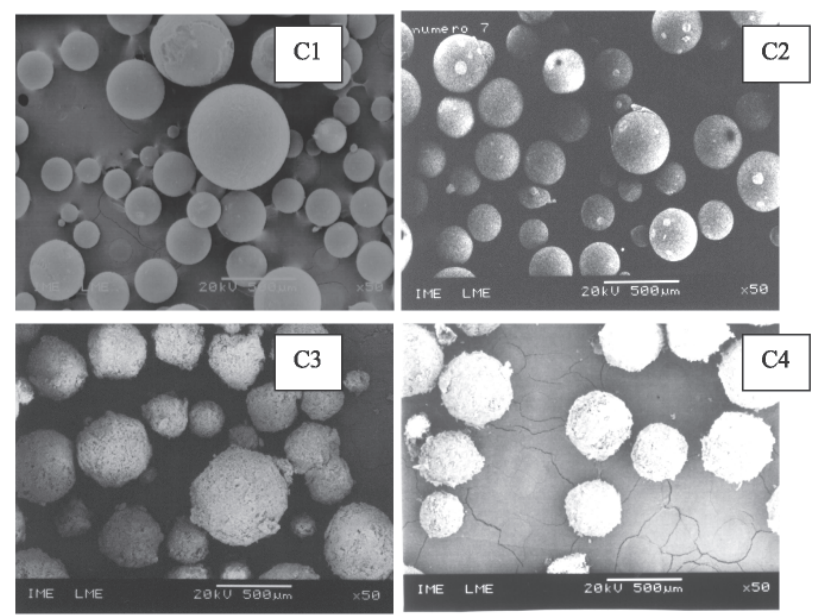

Figure 1. Morphological aspects of the 2VP and 4VP copolymers observed with SEM (magnification 50×).

The thermodynamic solvent-polymer interaction is well known to affect the pore physical structure. An indication of the solvent influence on the porous structure of polymer network may be related with the solubility parameter differences of the polymer and the diluent. ${ }^{24}$ The values of solubility parameter (SP) of the selected diluents are: $\mathrm{SP}_{\mathrm{TOL}}=18.2 \mathrm{MPa}^{1 / 2} ; \mathrm{SP}_{\mathrm{HEP}}=15.1 \mathrm{MPa}^{1 / 2}$. The SP of STY/DVB and VP/DVB copolymers depends on their cross-link degree, in that case the SP values for theses copolymers with $10 \%$ cross-link degree are respectively: 15.7 $\mathrm{MPa}^{1 / 2}$ and 27.6 $\mathrm{MPa}^{1 / 2} \cdot{ }^{25}$ As it was predictable, the copolymers have presented porous structure due to large difference between the SP values of diluents and copolymers. Since the porosities of $\mathrm{C} 1$ and $\mathrm{C} 2$ compared to $\mathrm{C} 3$ and $\mathrm{C} 4$ are very different among them, we have measured the pores characteristics by two different methods. The textural analysis shown on Table 2 has indicated that the copolymers present large pores and low specific areas. The copolymers based on 4VP are more 
Table 2. Porous characteristics of pyridinic copolymers in the dry state

\begin{tabular}{|c|c|c|c|c|}
\hline Copolymer & Bulk density/( $\left.\mathrm{g} \mathrm{cm}^{-3}\right)$ & Specific area/(m $\left.\mathrm{m}^{2} \mathrm{~g}^{-1}\right)$ & Average pore diameter/(§) & Pore volume $/\left(\mathrm{cm}^{3} \mathrm{~g}^{-1}\right)$ \\
\hline $\mathrm{C} 1$ & 0.35 & $37^{\mathrm{a}}$ & $226^{\mathrm{b}}$ & $0.23^{b}$ \\
\hline $\mathrm{C} 2$ & 0.33 & $43^{a}$ & $201^{\mathrm{b}}$ & $0.23^{\mathrm{b}}$ \\
\hline $\mathrm{C} 3$ & 0.27 & $77^{\mathrm{c}}$ & $5000^{c}$ & $1.21^{\mathrm{c}}$ \\
\hline $\mathrm{C} 4$ & 0.24 & $106^{c}$ & $814^{c}$ & $0.99^{c}$ \\
\hline
\end{tabular}

${ }^{\mathrm{a}}$ Measurement by BET; ${ }^{\mathrm{b}}$ Measurement by BJH; ${ }^{\mathrm{c}}$ Mercury porosimetry.

porous than 2VP ones. This could be explained by the phase separation (fixed pores), which occurs during the first stages of copolymerization being more accentuated when 4VP was employed. Hence, the presence of $n$-heptane in the diluent mixture (Table 1) contributes more to the polymer phase separation during this polar monomer incorporation.

This behavior could be attributed to a poorer solvation of the growing chains of poly4VP by $n$-heptane (nonsolvating diluent) compared to the other polymer. The large difference between SP of the copolymer and $\mathrm{SP}_{\mathrm{HEP}}$ explains the production of macroporous resins $(\mathrm{C} 3$ and $\mathrm{C} 4$ copolymers) showing that $n$-heptane is a poor solvent for this system with larger amount of 4VP. In addition, these resins present lower densities and diaphanous/opaque appearance when they were observed in an optical microscope. These results should be attributed to the higher polarity of 4VP than 2VP (dielectric constant, $(\varepsilon)$ $4 \mathrm{VP}=10.5$ and $2 \mathrm{VP}=9.12$ ), which should provoke an early phase separation. ${ }^{25}$ The porosity characteristics of copolymers could be confirmed by the SEM micrographs shown in Figures 1 and 2. Comparing the external surface of these resins, it is possible to see that the resins of the $4 \mathrm{VP}$ copolymers are rougher than of the $2 \mathrm{VP}$ one. In addition, the SEM micrographs with larger magnification $(5000 \times)$ show that the 4VP copolymers are more porous than the others (Figure 2). These images evidence that the 4VP copolymer networks are clearly macroporous, corroborating the textural analysis shown on Table 2.

Table 3 shows the swelling percentage of copolymers in different solvents aiming to select the one that should be employed for modifying the resins. As it can be seen in this table, methanol and anisole were good solvents for all resins. Therefore methanol was chosen for conducting the reaction of quaternization of $2 \mathrm{VP}$ and 4VP copolymers, due to the polarity and its low boiling point $\left(65^{\circ} \mathrm{C}\right)$ which is lower than acrylonitrile $\left(77^{\circ} \mathrm{C}\right)$. Although 4VP is more polar than 2VP, their copolymers (C3 and C4) are less swellable in the three polar solvents evaluated. Since the crosslinking degree among these copolymers is almost the same (around 10\%), this result could be explained by the large porosity of $4 \mathrm{VP}$ copolymer.

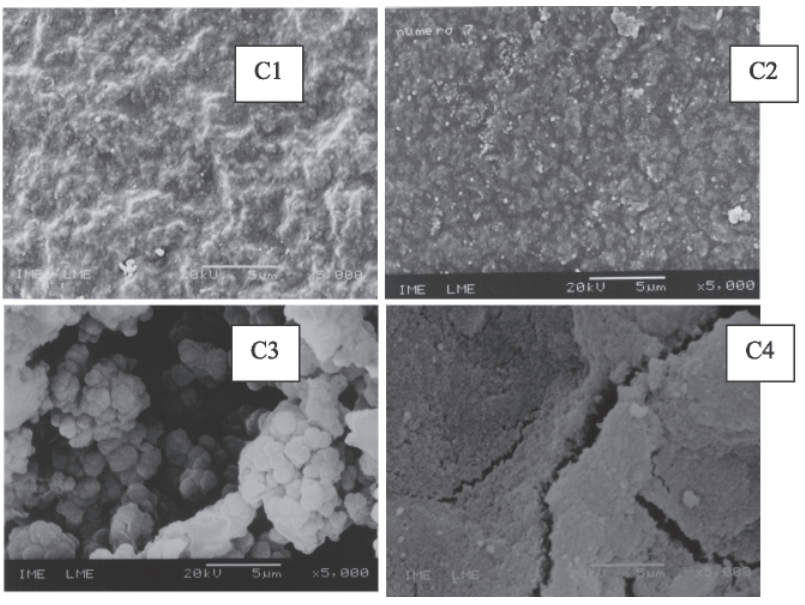

Figure 2. SEM photomicrographs of the 2VP and 4VP copolymers (magnification 5000×).

The pyridinic copolymers were modified with acrylonitrile to produce the quaternization derivatives. Some reaction parameters were investigated, such as amounts of $\mathrm{HCl}$ and acrylonitrile and also reaction time. Table 4 summarizes quaternization conditions of $2 \mathrm{VP}$ (reactions 1 to 7) and 4VP (reaction 8) copolymers, as well as their reaction extensions, which were determined by elemental analysis. Each reaction was repeated three times. For the reactions employing the 2VP copolymer, the highest level of quaternization was reached with the C2 copolymer (reaction 6). The ideal reaction time and molar ratio between $\mathrm{HCl}$ and acrylonitrile were respectively, $72 \mathrm{~h}$ and 1:4. This reaction condition was employed for 4VP copolymers (reaction 8). The best result (34\%) could be attributed to smaller steric hindrance than $2 \mathrm{VP}$ copolymers. Although the $\mathrm{C} 4$ presents a large surface area, its morphology is not appropriate (more defects, more cracks etc.) for extraction process.

Table 3. Swelling percentage of copolymers in different solvents

\begin{tabular}{lcccc}
\hline Copolymer & \multicolumn{4}{c}{ Swelling degree / (\%) } \\
\cline { 2 - 5 } & Anisole & 1,4-Dioxane & Methanol & Toluene \\
\hline C1 & 50 & 46 & 50 & 36 \\
C2 & 50 & 46 & 50 & 34 \\
C3 & 30 & 27 & 30 & 10 \\
C4 & 30 & 30 & 43 & 10 \\
\hline
\end{tabular}


Table 4. Reaction parameters of 2VP and 4VP copolymers with acrylonitrile

\begin{tabular}{|c|c|c|c|c|c|}
\hline Reactions & Sample ${ }^{a}$ & $\mathrm{HCl}$ amount $^{\mathrm{b}}$ & AcrylonitrileAmount ${ }^{\mathrm{b}}$ & Reaction time/h & Modification degree $/(\%)^{c}$ \\
\hline 1 & C1Q1 & 0.02 & 0.08 & 48 & 0 \\
\hline 2 & C1Q2 & 0.04 & 0.16 & 48 & 2 \\
\hline 3 & C1Q3 & 0.03 & 0.06 & 72 & 4 \\
\hline 4 & C2Q1 & 0.03 & 0.06 & 72 & 8 \\
\hline 5 & $\mathrm{C} 2 \mathrm{Q} 2$ & 0.01 & 0.06 & 72 & 0 \\
\hline 6 & C2Q3 & 0.02 & 0.08 & 72 & 22 \\
\hline 7 & $\mathrm{C} 2 \mathrm{Q} 4$ & 0.02 & 0.08 & 48 & 6 \\
\hline 8 & C3Q1 & 0.02 & 0.08 & 72 & 34 \\
\hline
\end{tabular}

${ }^{\mathrm{a}} \mathrm{C} 1$ and $\mathrm{C} 2$ are $2 \mathrm{VP}$ copolymer and $\mathrm{C} 3$ is $4 \mathrm{VP}$ copolymer (approx. 0.005 mole); ${ }^{\mathrm{b}}$ molar amount; ${ }^{\mathrm{c}}$ determined by elemental analysis.

Figure 3 shows the FTIR spectra of unmodified and quaternized copolymer. For C1Q3 resin, the nitrile characteristic absorption was displayed at $2243 \mathrm{~cm}^{-1}$. The spectra of quaternized resins also presented an absorption at $1620 \mathrm{~cm}^{-1}$ which was attributed to pyridinium. ${ }^{26}$ These results indicated clearly that the pyridinic units were modified by the quaternization of acrylonitrile. These absorptions also were observed for modified $4 \mathrm{VP}$ copolymer (C3Q1, Table 4). These results clearly indicate, that the quaternization of pyridinic units of opolymer was properly achieved. As indicated by the results of $\mathrm{CHN}$ analysis shown on Table 4, the highest level of quaternization was achieved for $\mathrm{C} 3 \mathrm{Q} 1$ resin compared to the other ones.

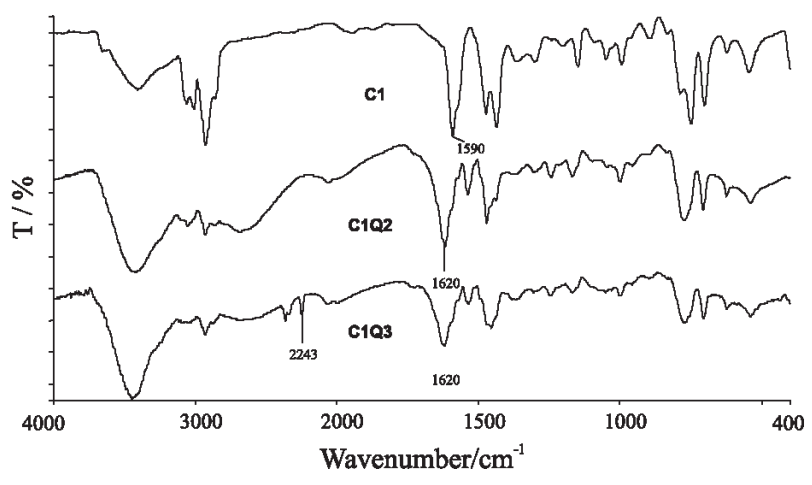

Figure 3. FTIR spectra of unmodified and quaternized 2VP copolymers.

Considering the higher extension modification degree, the 4-nitrophenol removal capacity modified copolymers (C2Q3 and C3Q1) was evaluated. The modified copolymers were compared with the unmodified ones $(\mathrm{C} 2$ and C3). First, the performance of these materials for the 4-nitrophenol removal was carried out at $\mathrm{pH} 5.6$ during different contact times. The results are summarized in Table 5.

The results have indicated that the modified copolymers present better 4-nitrophenol removal capacity (see Table 5). Additionally, the $\mathrm{C} 3 \mathrm{Q} 1 \mathrm{resin}$ had the best removal capacity and reached equilibrium faster than the others.
Table 5. Influence of contact time on the 4-nitrophenol adsorption

\begin{tabular}{lccc}
\hline Copolymer & \multicolumn{3}{c}{ 4-Nitrophenol removal/(\%) } \\
\cline { 2 - 4 } & $30 \mathrm{~min}$ & $60 \mathrm{~min}$ & $180 \mathrm{~min}$ \\
\hline C2 & 0 & 2 & 2 \\
C2Q3 & 75 & 80 & 85 \\
C3 & 3 & 17 & 29 \\
C3Q1 & 91 & 92 & 92 \\
\hline
\end{tabular}

Conditions: $0.3 \mathrm{~g}$ of the copolymer was added to $25 \mathrm{~mL}$ of the 4-nitrophenol aqueous solution; without $\mathrm{pH}$ control.

These aspects could be related to a higher hydrophilicity of the quaternized resins. Specifically, the C3Q1 better performance could be attributed to its higher chemical modification extension if compared to the $\mathrm{C} 2 \mathrm{Q} 3$ resin. Besides, it could also be attributed to its larger porosity (Table 2) considering the other materials (see Table 5). The copolymers C2Q3 and C3 had their best efficiency in 180 $\min$. The $\mathrm{C} 2$ copolymer did not present any removal of 4nitrophenol. This could be explained by its low porosity in relation to the $\mathrm{C} 3$ and the low hydrophilicity in relation to the quaternized resins.-Moreover, the time influence in relation to $\mathrm{C} 3$ resin could be due to its hydrofobicity, despite having large pores. This hydrophobicity decreases the diffusion processes of phenol (presented in the aqueous solution) in the active sites of the resin, so more time was needed to reach equilibrium.

The $\mathrm{pH}$ influence on the 4-nitrophenol removal from aqueous solution was evaluated at the contact time of 60 min (Table 6). The efficiency of quaternized copolymers was reduced neither in acid $\mathrm{pH}$ nor in basic $\mathrm{pH}$. This result suggests that new dipole interactions were predominant in relation to the $\pi-\pi$ interaction of non-modified copolymers. On the other hand, by the adsorption analysis with the $\mathrm{C} 3$ copolymer, we could observe that the $\mathrm{pH}$ has a strong influence on the 4-nitrophenol removal performance. This fact suggests the contribution of the type hydrogen bond interaction between the free-electron pairs of the pyridine nitrogen and hydroxyl phenolic hydrogen, at $\mathrm{pH}$ 5.6. 
Table 6. Influence of $\mathrm{pH}$ on the 4-nitrophenol adsorption

\begin{tabular}{lccc}
\hline Copolymer & \multicolumn{3}{c}{ 4-Nitrophenol removal/(\%) } \\
\cline { 2 - 4 } & $\mathrm{pH} 3.0$ & $\mathrm{pH} 5.6$ & $\mathrm{pH} 8.0$ \\
\hline C2 & 0 & 2 & 0 \\
C2Q3 & 81 & 80 & 79 \\
C3 & 6 & 17 & 4 \\
C3Q1 & 90 & 91 & 93 \\
\hline
\end{tabular}

Conditions: $0.3 \mathrm{~g}$ of the copolymer was added to $25 \mathrm{~mL}$ of the 4-nitrophenol aqueous solution; time $=60 \mathrm{~min}$.

These resins presented lower surface area compared to the Fontanals's ones and were more efficient for 4-nitrophenol extraction, showing that the chemical modification was an important goal to improve the adsorption efficiency of the pyridinic resin. ${ }^{27}$

The preliminary adsorption evaluation indicated that quaternization of pyridinic copolymers with acrylonitrile is an alternative for 4-nitrophenol adsorption.

\section{Acknowledgments}

The authors are grateful for the financial support from CAPES, FAPERJ and CNPq. We thank the following companies: Petroflex and Metacril for reagent donations; Nitriflex for reagents and elemental analysis; CENPES/ Petrobras for the surface area measurements (Ms. Sandra S. X. Chiaro).

\section{References}

1. Lacorte, S.; Barceló, D.; Chiron, S.; TrAC, Trends Anal. Chem. 1994, 13, 352.

2. Marcheterre, L.; Choudry, G.G.; Webster, B.R.G.; Rev. Environ. Contam. Toxicol. 1988, 103, 61 .

3. Lim, B.R.; Ahn, K.H.; Fujie, K.; Process Biochem. 2005, 40, 2603.

4. Bolzacchini, E.; Bruschi, M.; Hjorth, J.; Meinard, S.; Orlandi, M.; Rindone, B.; Rosenbohm, E.; Environm. Sci. Technol., 2001, 35,1791 .

5. Kuo, S.W.; Lin, C.L.; Chang, F.C.; Polymer 2002, 43, 3943

6. Malik, M.A.; Mukhtar, R.M.; Zaidi, S.A.R.; Ahmed, S.; Awan, M.A.; React. Funct. Polym. 2002, 51, 117.

7. Gargallo, L.; Miranda, B.; Leiva, A.; Rios, H.; González-Nilo, F.; Radie, D.; J. Colloid Interface Sci. 2004; 271,181.
8. Malik, M.A.; Ur-Rehman, E.; Naheed, R.; Alam, N.M.; React. Funct. Polym. 2002; 50, 125.

9. Gutanu, V.; Luca, C.; Turta, C.; Neagu, V.; Sofranschi, V.; Cherdivarenco, M.; Simionescu, B.C.; J. Appl. Polym. Sci. 1996, 59, 1371.

10. Jandrey, A.C.; Aguiar, A.P.; Aguiar, M.R.M.P.; Santa Maria, L.C.; Thermochim. Acta 2004; 424, 63.

11. Li, G.; Shen, J.; J. Appl. Polym. Sci. 2000, 78, 676.

12. Santa Maria, L.C.; Aguiar, A.P.; Aguiar, M.R.M.P.; Jandrey, A..C.; Mazzei, J.L.; Felzenszwalb, I.; J. Appl. Polym. Sci. 2004, 93, 972.

13. Svec, F.; Konecna, I.; Fréchet, J.M.J.; Meftahi, M.V.; React. Funct. Polym. 1985, 3, 151.

14. Fréchet, J.M.J.; Warnock, J.; Farrall, M.J.; J. Org. Chem. 1978, 4, 2618.

15. Fréchet, J.M.J.; Darling, P.; Farrall, M.J.; J. Org. Chem. 1981, 46, 1728 .

16. Lima Luz, C.T.; Coutinho, F.M.B.; Polymer 2001, 42, 4931.

17. Coutinho, F.M.B.; Carvalho, D.L.; La Torre Aponte, M.L.; Barbosa, C.C.R.; Polymer 2001, 42, 43.

18. Okay, O.; Soner, E.; Grungor, A.; Balkas, T.L.; J. Appl. Polym. Sci. 1986, 31, 1785.

19. Li, Y.; Yang, M.J.; She, Y.; Sens. Actuators, B 2005, 107, 252.

20. Teixeira, V.G.; Coutinho, F.M.B.; Petrocínio, F.R.M.; Gomes, A.S.; J. Braz. Chem. Soc. 2005, 16, 926

21. Santa Maria, L.C.; Aguiar, A.P.; Aguiar, M.R.M.P.; Jandrey, A.C.; Guimarães, P.I.C.; Nascimento, L.G.; Mater. Lett. 2004; $58,563$.

22. Krzysztof, M.; Thomas, P.D.; Handbook of Radical Polymerization, Wiley-Interscience: New York, 2002.

23. Lambert, J.B.; Shurvell, H.F.; Lightner, D.; Cooks, R.G.; Introduction to Organic Spectroscopy, $1^{\text {st }}$ ed., Macmillan Publishing Co.:New York, 1987.

24. Riqueza, E.C.; Aguiar, A.P.; Santa Maria, L.C.; Aguiar, M.R.M.P.; Polym. Bull. 2002, 48, 407.

25. Brandrup, J.; Immergut, E.H.; Polymer Handbook, $3^{\text {rd }}$ ed., Wiley: New York, 1989.

26. Yang, J.M.; She, Y.L.; J. Mater. Sci. Lett. 2002, 21, 1477.

27. Fontanals, N.; Marcé, R.M.; Gália, M.; Borrull, F.; J. Polym. Sci., Part A: Polym. Chem. 2003, 41, 1927.

Received: December 8, 2005

Web Release Date: March 9, 2007 